\title{
Postprandial serum endotoxin in healthy humans is modulated by dietary fat in a randomized, controlled, cross-over study
}

Joshua M. Lyte ${ }^{1,2,3^{*}}$, Nicholas K. Gabler ${ }^{2}$ and James H. Hollis ${ }^{1}$

\begin{abstract}
Background: High-fat diets may contribute to metabolic disease via postprandial changes in serum endotoxin and inflammation. It is unclear how dietary fat composition may alter these parameters. We hypothesized that a meal rich in n-3 ( $\omega 3)$ fatty acids would reduce endotoxemia and associated inflammation but a saturated or n-6 ( $\omega 6)$ fatty acid-rich meal would increase postprandial serum endotoxin concentrations and systemic inflammation in healthy adults.
\end{abstract}

Methods: Healthy adults ( $n=20$; mean age $25 \pm 3.2$ S.D. years) were enrolled in this single-blind, randomized, crossover study. Participants were randomized to treatment and reported to the laboratory, after an overnight fast, on four occasions separated by at least one week. Participants were blinded to treatment meal and consumed one of four isoenergetic meals that provided: 1) $20 \%$ fat (control; olive oil) or $35 \%$ fat provided from 2) n-3 (w3) (DHA = 500 mg; fish oil); 3) n-6 (w6) (7.4 g; grapeseed oil) or 4) saturated fat (16 g; coconut oil). Baseline and postprandial blood samples were collected. Primary outcome was defined as the effect of treatment meal on postprandial endotoxemia. Serum was analyzed for metabolites, inflammatory markers, and endotoxin. Data from all 20 participants were analyzed using repeated-measures ANCOVA.

Results: Participant serum endotoxin concentration was increased during the postprandial period after the consumption of the saturated fat meal but decreased after the n-3 meal $(p<0.05)$. The $n-6$ meal did not effect a different outcome in participant postprandial serum endotoxin concentration from that of the control meal $(p>0$. 05). There was no treatment meal effect on participant postprandial serum biomarkers of inflammation. Postprandial serum triacylglycerols were significantly elevated following the n-6 meal compared to the n-3 meal. Non-esterified fatty acids were significantly increased after consumption of the saturated fat meal compared to other treatment meals.

Conclusions: Meal fatty acid composition modulates postprandial serum endotoxin concentration in healthy adults. However, postprandial endotoxin was not associated with systemic inflammation in vivo.

Trial registration: This study was retrospectively registered at clinicaltrials.gov as NCT02521779 on July 28, 2015.

Keywords: Endotoxin, Lipopolysaccharide, Diet, Lipid, Fat, Oil, Inflammation

\footnotetext{
* Correspondence: joshua.lyte@ucc.ie

${ }^{1}$ Department of Food Science and Human Nutrition, lowa State University, Ames, IA 50011, USA

${ }^{2}$ Department of Animal Science, lowa State University, Ames, IA 50011, USA

Full list of author information is available at the end of the article
}

\section{Ciomed Central}

(c) The Author(s). 2016 Open Access This article is distributed under the terms of the Creative Commons Attribution 4.0 International License (http://creativecommons.org/licenses/by/4.0/), which permits unrestricted use, distribution, and reproduction in any medium, provided you give appropriate credit to the original author(s) and the source, provide a link to the Creative Commons license, and indicate if changes were made. The Creative Commons Public Domain Dedication waiver (http://creativecommons.org/publicdomain/zero/1.0/) applies to the data made available in this article, unless otherwise stated. 


\section{Background}

In recent years, accumulating research has demonstrated a link between dietary fat and endogenous endotoxin in relation to metabolic inflammation [1, 2]. Current evidence suggests that dietary fat modulates plasma endotoxin concentration which is associated with low-grade systemic inflammation and is implicated in the development of dysregulated metabolism [3-6]. Endotoxin, also known synonymously as lipopolysaccharide (LPS), is considered a major predisposing factor for inflammation-associated diseases such as atherosclerosis, sepsis, obesity, type 2 diabetes and Alzheimer's [7-9]. However, the effect of dietary fat on the plasma endotoxin remains poorly understood as it is not known if it is the total fat content of a meal or its fatty acid composition exerts the primary effect.

Previous studies have shown that consuming a high fat meal (50 g fat) is associated with a post-prandial increase in plasma [4] and serum [10] endotoxin concentrations in adult humans. Limited evidence also suggests that the type of fatty acid may be important with one study showing that consuming oleic acid-rich peanuts reduced serum endotoxin in healthy men compared to when they consumed standard peanuts [11]. A recent study reported that, using an ex vivo swine intestine model, mucosal to serosal endotoxin transport was decreased with a high docosahexaenoic acid (DHA) and eicosapentaenoic acid (EPA)-meal but increased after a saturated fatty acid rich (coconut oil)-meal; however, the inflammatory response in these animals was not investigated [12].

High-fat diets have been linked with elevated blood concentrations of multiple inflammatory markers including interleukin (IL)-6 [13], IL-8 [14], and tumor necrosis factor- $\alpha$ (TNF- $\alpha$ ) [15]. As bacterial endotoxin is recognized by the body's innate immune system and is a potent initiator of inflammation processes [16], a postprandial increase in circulating endotoxin offers a potential mechanistic explanation for the inflammatory response [4]. However, while blood endotoxin concentration has been associated with incidence of inflammation [17] and metabolic dysfunction $[18,19]$, others have reported an in vitro, but not in vivo, postprandial relationship between blood endotoxin concentration and inflammation following the consumption of high-fat meals [4].

Because the link between dietary fat intake, endotoxin, and inflammation is unclear, the primary objective of this study was to determine the effect of dietary fatty acid composition on postprandial endotoxemia in healthy subjects. Based on a previous study [12] we hypothesized that postprandial endotoxin concentrations and markers of inflammation in healthy adults would be increased by meals high in saturated or n- 6 fatty acids, but reduced by meals enriched in $n-3$ polyunsaturated fatty acids. Pre- and postprandial serum was assayed for endotoxin, inflammatory markers, and metabolites.

\section{Methods}

\section{Human subjects}

Male and female participants (Table 1) [(average age 25 y (SD: $3.2 \mathrm{y}$ ); average body mass index (BMI) $22.4 \mathrm{~kg} / \mathrm{m}^{2}$ (SD: $2 \mathrm{~kg} / \mathrm{m}^{2}$ ); average weight $65.6 \mathrm{~kg}$ (SD: $\left.8 \mathrm{~kg}\right)$ ] were recruited via a mass email to faculty, staff, and students of Iowa State University or through personal contact during Spring and Fall of 2014. Inclusion criteria were age between 18 and $40 \mathrm{y}, \mathrm{BMI} \geq 19.9$ and $\leq 24.9$, less than $2 \mathrm{~kg}$ weight change in the previous 3 months and a willingness to eat the test meals. Exclusion criteria were the presence of acute or chronic disease, use of tobacco products, consumption of more than 21 units of alcohol per week, use of anti-inflammatory medication, or a history of macronutrient malabsorption.

\section{Study design}

This study used a randomized, single-blind, cross-over design. After being recruited to the study, participants $(n=20)$ were randomized to a treatment order (Fig. 1). Participants were required to report to the laboratory first thing in the morning following an overnight fast of at least 12 hours on four separate occasions each separated by at least 7 days.

On the evening before each test session, participants were required to eat a standardized meal that provided $50 \%$ of the participant's estimated energy requirements and contained $50 \%$ carbohydrate, $15 \%$ protein, and $35 \%$ fat. The participant's estimated daily energy requirements were determined using validated equations [20]. On the morning of each test session, participants were required to arrive at the laboratory at 0715 . An indwelling catheter was inserted into the antecubital vein of each participant's non-dominant arm and a baseline blood draw $(10 \mathrm{~mL})$ was taken (time point $\mathrm{t}=0)$. Participants were then provided with the relevant test meal that was consumed in its entirety within $15 \mathrm{~min}$. On each occasion, participants were blinded to which treatment meal they would be provided that morning. All treatment meals were served in a uniform, visually indistinguishable fashion to avoid participant recognition of treatment meal. Participants remained in the laboratory for five and a half hours during which additional blood draws (10 $\mathrm{mL}$ per blood draw) were taken at time points

Table 1 Demographics of subjects $(n=20)$ that successfully completed the study ${ }^{a}$

\begin{tabular}{lll}
\hline & Male & Female \\
\hline Number of subjects & 12 & 8 \\
Average age $(\mathrm{y})$ & 25 & 25 \\
Weight $(\mathrm{kg})$ & 68.9 & 59.4 \\
Body mass index & 22.7 & 22.3 \\
\hline
\end{tabular}

${ }^{a}$ Participant information about race and ethnicity was not collected 


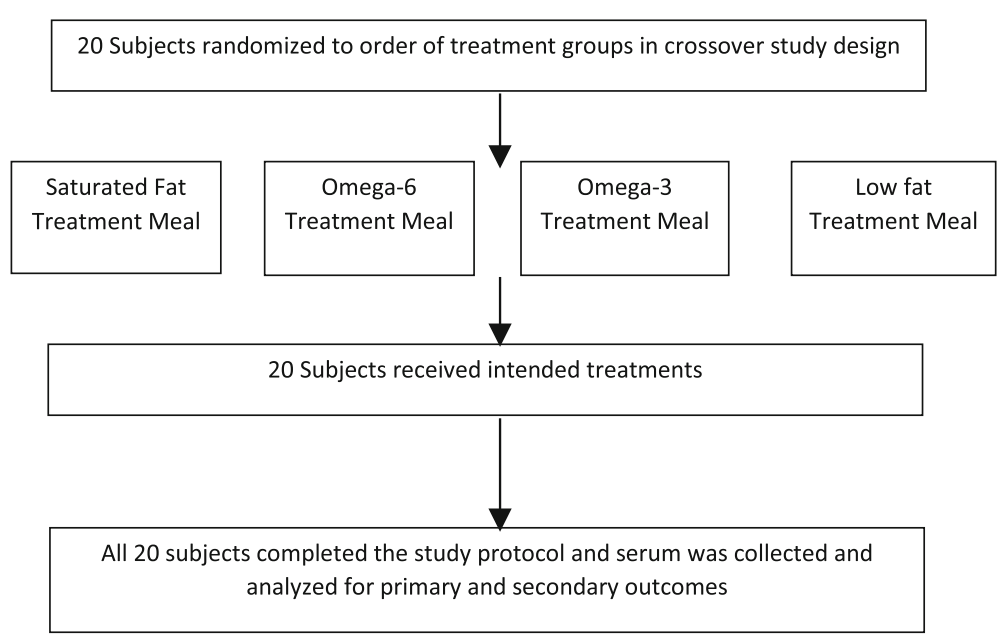

Fig. 1 Flow chart of subjects $(n=20)$ through the study

t0+ 1, 2, 3, 4, and $5 \mathrm{~h}$. During this time, participants were allowed to perform sedentary activities (e.g. watch television, use their computer) but were not allowed to consume any food or drink except water. Following the final blood draw at $\mathrm{t} 0+5 \mathrm{~h}$, the indwelling catheter was removed and the participant permitted to leave the laboratory.

Immediately following venipuncture, blood was allowed to clot in pyrogen-free blood collection tubes for $45 \mathrm{~min}$, followed immediately by centrifugation $(15 \mathrm{~min}, 2000 \times g$, $4{ }^{\circ} \mathrm{C}$ ), and stored in pyrogen-free tubes (Fisher Scientific, Pittsburgh, PA) at $-80{ }^{\circ} \mathrm{C}$ until further analysis or transferred into standard plastic screw-cap vials (Quest Diagnostics, Madison, NJ) according to company instructions for same-day pickup and shipment to Quest Diagnostics for analysis of serum metabolites.

\section{Test meals}

Each test meal provided $25 \%$ of the participant's estimated daily energy requirements as determined using validated equations [20]. The test meal was a porridge made with quick-ready oatmeal (Hy-Vee Supermarkets, Ames, IA) prepared with water according to the manufacturer's instructions. To this oatmeal, 1) coconut oil (Spectrum, Lake Success, NY), 2) olive oil (Crisco, Orville, OH), 3) grapeseed oil (Pompeian, Baltimore, MD) or 4) fish oil (Carlson, Arlington Heights, IL) was added in order to provide each of the four test meals a unique macronutrient (Table 2) and fatty acid profile (Table 3). $60 \mathrm{~g} \pm 17 \mathrm{~g}$ of hard-boiled egg (Crystal Farms 6 peeled hard-boiled eggs ready-to-eat, Lake Mills, WI), $201 \mathrm{~g} \pm 26 \mathrm{~g}$ of fat-free skim milk (HyVee fat free skim milk, Des Moines, IA), and $184 \mathrm{~g} \pm 33 \mathrm{~g}$ of orange juice (Tropicana Pure Premium No Pulp, Bradenton, FL) were served with the porridge. The participants were required to eat the test meal in its entirety within $15 \mathrm{~min}$ of serving.

\section{Bomb calorimetry}

The energy $(\mathrm{kcal} / \mathrm{g})$ of each test meal was determined using bomb calorimetry. Each test meal was prepared identical as if it were to be served to a participant. Meals were homogenized using a food-grade commercial blender (Model HBH450, Hamilton Beach Commercial, Glen Allen, VA) on high setting for $1 \mathrm{~min}$ and then passed through a $2 \mathrm{~mm}$ sieve (Advantech $2.00 \mathrm{~mm}$ USA standard testing sieve No. 10, New Berlin, WI). Aliquots were weighed and then lyophilized at $-55{ }^{\circ} \mathrm{C}$ using a Uni-Trap Model 10-100 (The Virtis Company, Gardiner, NY). Lyophilized samples were ground and passed through a $1 \mathrm{~mm}$ screen before being pelleted into duplicate $\sim 1.00 \mathrm{~g}$ pellets using a manual pellet press (Parr

Table 2 Treatment meal composition

\begin{tabular}{lllll}
\hline & Low-fat & $\begin{array}{l}\text { High fat } \\
(\mathrm{n}-3)\end{array}$ & $\begin{array}{l}\text { High fat } \\
(\mathrm{n}-6)\end{array}$ & $\begin{array}{l}\text { High fat } \\
\text { (saturated) }\end{array}$ \\
\hline $\begin{array}{l}\text { Carbohydrate } \\
(\%)^{\mathrm{a}}\end{array}$ & 65 & 50 & 50 & 50 \\
Protein (\%) & 15 & 15 & 15 & 15 \\
Total fat (\%) & 20 & 35 & 35 & 35 \\
Saturated fat (\%) & 5 & 10 & 10 & 15 \\
$\begin{array}{l}\text { Total n-6 fatty } \\
\text { acids (\%) }\end{array}$ & 2 & 2 & 7 & 2 \\
EPA + DHA fatty & 0 & 0.5 & 0 & 0
\end{tabular}

acids (\%)

\begin{tabular}{lllllllll} 
& Mean & SEM & Mean & SEM & Mean & SEM & Mean & SEM \\
Energy $(\mathrm{kcal} / \mathrm{g})^{\mathrm{b}}$ & $4.96^{\mathrm{a}}$ & 0.04 & $4.90^{\mathrm{a}}$ & 0.01 & $5.09^{\mathrm{a}}$ & 0.05 & $5.22^{\mathrm{b}}$ & 0.01 \\
$\begin{array}{l}\text { Endotoxin } \\
\text { (EU/g) }\end{array}$ & $89.66^{\mathrm{a}}$ & 3.29 & $72.97^{\mathrm{b}}$ & 1.07 & $72.72^{\mathrm{b}}$ & 0.63 & $65.98^{\mathrm{c}}$ & 0.51 \\
\hline
\end{tabular}

a Values (\%) are based on $25 \%$ of participant estimated daily energy requirements

${ }^{\mathrm{b}}$ Each test meal was bombed in duplicate as described in Methods. Test meals were assayed in duplicate using LAL kinetic chromogenic endotoxin assay. Values within the same row but with different superscript letters are significant at the $p<0.05$ level 
Table 3 Fatty acid composition of test meals ${ }^{a, b}$

\begin{tabular}{|c|c|c|c|c|c|}
\hline Lipid (C:D) & Lipid common name & Low-fat & High fat (n3) & High fat (n6) & High fat (saturated) \\
\hline $8: 0$ & Caprylic & - & 1.1 & - & 2.9 \\
\hline 10:0 & Capric & - & 0.9 & 1.1 & 2.7 \\
\hline 12:0 & Lauric & - & $8.5^{c}$ & $8.4^{c}$ & $23.8^{d}$ \\
\hline 14:0 & Myristic & $0.2^{c}$ & $5.0^{d}$ & $3.8^{\mathrm{d}}$ & $10.6^{\mathrm{e}}$ \\
\hline 16:0 & Palmitic & 16.4 & 17.1 & 14.2 & 15.9 \\
\hline $16: 1$ & Palmitoleic & 1.1 & 2.5 & 0.7 & 0.8 \\
\hline 18:0 & Stearic & 4.3 & 4.9 & 5.0 & 4.7 \\
\hline $18: 1 \mathrm{n} 9 \mathrm{cis}$ & Oleic & $57.3^{b}$ & $35.6^{c}$ & $31.4^{c}$ & $24.8^{e}$ \\
\hline $18: 2 \mathrm{n} 6 \mathrm{cis}$ & Linoleic & $16.8^{b}$ & $13.0^{d}$ & $31.2^{\mathrm{e}}$ & $10.3^{d}$ \\
\hline 20:0 & Arachidic & 0.2 & 0.1 & 0.1 & 0.1 \\
\hline 18:3 n3 & a-Linolenic & 0.8 & 0.7 & 0.5 & 0.4 \\
\hline 20:1 n9 & Eicosenoic & 0.3 & 0.4 & 0.2 & 0.2 \\
\hline 20:4 n6 & Arachidonic & 0.6 & 0.8 & 0.6 & 0.7 \\
\hline 20:5 n3 & Eicosapentaenoic & - & 3.0 & - & - \\
\hline $22: 6$ n3 & Docosahexaenoic & - & 2.3 & - & - \\
\hline Other & & 2.0 & 4.1 & 2.8 & 2.1 \\
\hline$n-6: n-3$ & & 21.7 & 2.3 & 63.6 & 27.5 \\
\hline Saturated & & 21.1 & 32.6 & 32.6 & 60.7 \\
\hline$n-3$ & & 0.8 & 6 & 0.5 & 0.4 \\
\hline$n-6$ & & 17.4 & 13.8 & 31.8 & 11 \\
\hline
\end{tabular}

${ }^{a}$ All values are expressed as percent of total fatty acids from a lipid extract prepared from duplicate samples of each test meal as described in the Methods; values within the same row but with different superscript letters (e.g. c, d, or e) are significantly different at the $p<0.05$ level

b ; not detected

Instrument Co., Moline, IL). Pellets were placed within a model 1108 oxygen bomb (Parr Instrument Co.) and bombed in a 6200 Isoperibol calorimeter (Parr Instrument Co.). Each test meal was analyzed in duplicate with an accepted CV of less than $2 \%$ between duplicate samples. Calorimetry standard $1.00 \mathrm{~g}$ benzoic acid pellets (Parr Instrument Co.) were used to calibrate each bomb before the analysis of test meal pellets.

\section{Limulus amebocyte lysate assays}

Participant serum and test meal endotoxin concentrations were determined using the kinetic chromogenic limulus amebocyte lysate (LAL) assay (Lonza, Switzerland). Endotoxin concentration was expressed as endotoxin units (EU) per $\mathrm{mL}$. Meals were freshlyprepared identically as if they were to be served to a participant. Prepared meals were then placed into separate sterile Whirl-pak filter bags (Nasco, Fort Atkinson, WI) and homogenized in a Stomacher 3500 (Seward, Davie, FL) for $2 \mathrm{~min}[21,22]$. Aliquots of the homogenized meal filtrate were collected into pyrogen-free tubes and stored at $-80{ }^{\circ} \mathrm{C}$ until analysis by the endotoxin assay. To minimize any impact of repeated freeze-thaw cycle on endotoxin-activity, serum and meal samples were thawed a single time for endotoxin assay. A positive product control (PPC) recovery test of an endotoxin spike of known concentration was performed in serum and in homogenized meal filtrate per LAL kit manufacturer instructions (data not shown). A dilution ratio of homogenized meal filtrate or serum: LAL-grade water of 1:100 provided a PPC recovery of the endotoxin spike within manufacturer recommendation of 50-200\%. Meticulous attention was given to the handling of serum and meal samples and the materials used in the endotoxin analysis to avoid contamination with exogenous endotoxin. Pipet tips, dilution tubes, 96-well microtiter plates, and reagent reservoir for use with a multichannel pipet were all certified to contain endotoxin concentrations $<0.005 \mathrm{EU} / \mathrm{mL}$ (Lonza, Switzerland).

Participant serum and meal samples were diluted 1:100 in LAL-grade water (Lonza, Switzerland) and heated at $70{ }^{\circ} \mathrm{C}$ for $15 \mathrm{~min}$ in order to heat-inactivate enzymatic activity that may affect endotoxin detection by the LAL method. $100 \mu \mathrm{L}$ of each heat-treated serum and meal sample was plated in duplicate on endotoxinfree 96-well plates and incubated in a PowerWave HT microplate reader (Biotek, Winooski, VT) at $37{ }^{\circ} \mathrm{C}$ for $10 \mathrm{~min}$. At the completion of the incubation period, the plate was removed from the plate reader and $100 \mu \mathrm{L}$ of LAL reagent was added to each sample well on the 96- 
well plate. The plate was then read at an absorbance of $405 \mathrm{~nm}$ according to the LAL-assay manufacturer's instructions. The assay result of each serum sample was accepted if the intra-assay $\mathrm{CV}$ between duplicate wells was below $10 \%$. Endotoxin concentrations were generated based on a standard curve constructed from a kitsupplied endotoxin standard prepared in LAL-grade water. The standard curve was constructed according to manufacturer's instructions and provided an endotoxin detection range from $0.005 \mathrm{EU} / \mathrm{mL}-50 \mathrm{EU} / \mathrm{mL}$. All LAL-kits utilized in this study were verified as from the same manufacturing lot in order to eliminate potential impact on endotoxin measurements due to inter-lot kit variation.

\section{Biomarkers of inflammation assays}

A magnetic, fluorescent bead-based immunoassay (BioPlex pro human cytokine group I 4-plex kit, Bio-Rad, Hercules, CA) was used to assay all serum samples for the cytokines IL-6, IL-8, IL-10, and TNF- $\alpha$. All Bio-Plex assays were performed on a Bio-Plex 200 system (Bio$\mathrm{Rad})$ and run according to manufacturer instructions. In brief, serum samples were diluted 1:4 in kit-supplied sample diluent and run in duplicate on kit-supplied 96well plates. A standard curve for each analyte was constructed from the kit-supplied lyophilized standard reconstituted in kit-provided standard diluent and a minimum bead count of 50 beads per analyte was acquired for each well. Bio-Plex Manager software standard edition version 6.1 (Bio-Rad) was used to collect the mean fluorescent intensity of each cytokine-specific bead region and convert the data using the standard curve into reportable concentrations $(\mathrm{pg} / \mathrm{mL})$. The reported concentration of each analyte was the average between duplicate wells.

C-reactive protein (CRP) content of each serum sample was determined via a nephelometric method performed by Quest Diagnostics (test ordering code 4420). CRP results were reported via delivered mail and expressed in $\mathrm{mg} / \mathrm{dL}$.

\section{Metabolite assays}

All serum samples were assayed via spectrophotometric methods for concentrations of triacylglycerols (test ordering code 896) and non-esterified fatty acids (NEFA) (test ordering code 449) by Quest Diagnostics. Triacylglycerols are expressed in $\mathrm{mg} / \mathrm{dL}$, while NEFA are expressed as $\mathrm{mmol} / \mathrm{L}$.

\section{Fatty acid analysis}

Freshly-prepared porridge test meals were homogenized with egg, skim milk, and orange juice in a food-grade commercial blender (Model HBH450, Hamilton Beach Commercial, Glen Allen, VA) on high setting for $1 \mathrm{~min}$.
Homogenized test meals were then passed through a $2.00 \mathrm{~mm}$ sieve (Advantech $2.00 \mathrm{~mm}$ USA standard testing sieve No. 10, New Berlin, WI) and aliquots were collected for immediate lipid extraction according to established methodology [23]. Extracted lipids were dried under nitrogen gas before undergoing transesterification into fatty acid methyl esters using an acetyl chloride/methanol method [24]. In brief, $1 \mathrm{~mL}$ of methanol was added to $40 \mathrm{mg}$ of dried extracted lipids. Samples were then vortexed, during which $100 \mu \mathrm{L}$ of acetyl chloride was added, and immediately purged under nitrogen gas and capped. Samples were heated for $1 \mathrm{~h}$ at $80^{\circ} \mathrm{C}$, and then allowed to cool to room temperature. Esterified lipids were transferred to a gas chromatography vial, purged under nitrogen gas and stored at $-20{ }^{\circ} \mathrm{C}$ until injection into the gas chromatograph (GC). Unless otherwise noted, all chemical reagents were analytical standard-grade and purchased from Acros Organics (Bridgewater, NJ).

Fatty acid methyl esters were analyzed in duplicate on a GC (Model 3800; Varian Analytical Instruments, Walnut Creek, CA) equipped with a SP-2380 (100 m × $0.25 \mathrm{~mm}$ I.D., $0.20 \mu \mathrm{m}$ ) capillary column (Supelco, Bellefonte, PA). Helium was the carrier gas with a flow rate of $2 \mathrm{~mL} / \mathrm{min}$. The GC injection port temperature was $220{ }^{\circ} \mathrm{C}$ and operated in standard split/splitless mode. The $\mathrm{GC}$ oven was maintained at $70{ }^{\circ} \mathrm{C}$ for $4 \mathrm{~min}$, then increased to $175{ }^{\circ} \mathrm{C}$ at a rate of $13{ }^{\circ} \mathrm{C} / \mathrm{min}$ and isothermally held for $27 \mathrm{~min}$, and then increased to a final temperature of $215{ }^{\circ} \mathrm{C}$ at a rate of $4{ }^{\circ} \mathrm{C} / \mathrm{min}$ and isothermally held for $28 \mathrm{~min}$. Test meal fatty acid profiles were analyzed using commercial software (Varian Star Chromatography Workstation Version 6.41, Walnut Creek, CA). Peak identification was validated by relative retention times with known reference standards (Supelco, Bellefonte, PA) and methyl tricosanoate (Nu-Chek Prep, Elysian, MN).

\section{Statistical analysis}

The primary outcome of this study was the effect of test meal fatty acid composition on postprandial serum endotoxin concentration. The secondary outcome was the effect of the test meal on the serum postprandial concentration of biomarkers of inflammation and metabolites. Mean and standard error were calculated for all study variables. Treatment effects of the test meal on serum endotoxin, inflammatory markers and metabolites were analyzed using a mixed model ANCOVA using treatment and time point as repeated measures and baseline as a covariate. All post-hoc, pairwise comparisons were performed using Bonferroni adjustments. Measured endotoxin values were log-transformed to normalize data distribution before parametric statistical analysis. Shapiro-Wilk normality test was employed to 
confirm log-transformed data were Gaussian. Data was analyzed using SPSS software (version 22; IBM, Armonk, NY). Statistical significance was set at $p<0.05$. A power calculation was done for Bonferroni multiple comparisons and it was estimated that a sample size of 16 individuals would be sufficient to detect a one SD difference with $\alpha=0.05$ and $\beta=.80$. Participants were randomly assigned to treatment sequence using a Latin Square design.

\section{Results}

\section{Test meal fatty acid profiles}

The unique fatty acid compositions of each of the four test meals are presented in Table 3. The saturated fat test meal contained a high percentage $(60.7 \%)$ of several saturated fatty acids found in coconut oil including lauric, myristic, and palmitic fatty acids. Compared to the saturated fat meal, the n-3 test meal contained a lower total percentage of saturated fatty acids (32.6\%). Moreover, the n-3 test meal contained both docosahexaenoic and eicosapentaenoic omega- 3 fatty acids that were not present in the saturated fat meal. The low-fat test meal primarily contained fatty acids found in olive oil, including oleic (57.3\%), palmitic (16.4\%), and linoleic (16.8\%) acids. The $\mathrm{n}-6$ test meal contained a high percentage of fatty acids found in grapeseed oil including linoleic (31.2\%), oleic (31.4\%), palmitic (14.2\%), and stearic (5.0 \%) acids.

\section{Test meal energy and endotoxin contents}

The energy content $(\mathrm{kcal} / \mathrm{g})$ and endotoxin $(\mathrm{EU} / \mathrm{g})$ contents of each of the four test meals is reported in Table 2. The mean energy content of the four test meals was 5.0 $\pm 0.04 \mathrm{kcal} / \mathrm{g}$ (dry weight basis). The meal endotoxin concentrations ranged from 65.9 to $89.6 \mathrm{EU} / \mathrm{g}$ (Table 2).

\section{Kinetic chromogenic LAL assay of serum endotoxin}

All subjects, regardless of treatment group or day of laboratory visit, had detectable levels of endotoxin in their serum at baseline measurement. Average participant baseline endotoxin concentration was $0.365 \pm 0.09 \mathrm{EU} /$ $\mathrm{mL}$. To ensure baseline endotoxin values were not the result of exogenous contamination from the materials used in the isolation of serum, control vessels were included and assayed identical to the vessels that contained human tissue. All control tubes had endotoxin levels of $<0.005 \mathrm{EU} / \mathrm{mL}$ as measured by the LAL assay. Accuracy of baseline endotoxin values was validated by repeat LAL assay of randomly selected baseline serum samples on two separate days via two separate LAL kits with the same manufacture lot number (data not shown).

There was a significant main effect of test meal on serum endotoxin concentration $(F(3,83)=3.104 ; p<0.05)$.
Post hoc analysis revealed that serum endotoxin was lower following the $\mathrm{n}-3$ meal compared to the saturated fat meal $(p<0.05)$. Comparison of the mean endotoxin values of the three high fat diets to the low fat diet did not yield a statistically significant $(p<0.05)$ difference suggesting that absolute fat intake does not influence post-prandial endotoxemia. In addition, there was a significant main effect of time on serum endotoxin $(F(4,229)=2.972 ; p<0.05)$. Post hoc analysis revealed a statistically significant difference between timepoints $60 \mathrm{~min}$ and $240 \mathrm{~min}$ and $120 \mathrm{~min}$ and $240 \mathrm{~min}(p<0.05)$. The treatment $\mathrm{x}$ time interaction was not statistically significant.

\section{Quantitative determination of multiple serum biomarkers of systemic inflammation}

Participants' baseline and postprandial serum concentrations of C-reactive protein measured below the detectable limit $(<0.10 \mathrm{mg} / \mathrm{dL})$ of the assay performed by Quest Diagnostics. Fluorescent bead-based immunoassay (Bio-Plex) of each participant serum sample revealed concentrations of IL-6, IL-8, IL-10, and tumor necrosis factor- $\alpha$ were not significantly $(p>0.05)$ different from baseline measurement or between treatment meals (data not shown).

\section{Measurement of serum triacylglycerol and non-esterified fatty acids}

Mean postprandial serum concentrations of triacylglycerols and non-esterified fatty acids displayed similar changefrom-baseline trends irrespective of test meal (Fig. 2). The mean participant baseline measurement of serum triacylglycerols concentration $(\mathrm{mg} / \mathrm{dL})$ was $89 \pm 2$. There was a significant main effect of treatment meal on serum triacylglycerols concentration $(F(3,58)=3.865 ; p<0.05)$. Post-hoc analysis indicated serum triacylglycerols concentration following the $\mathrm{n}-6$ meal to be statistically higher $(p<0.05)$ than after consumption of the n-3 meal (Fig. 2a). A significant main effect was also found of time on triacylglycerols concentration $(F(4,255)=29.805 ; p<0.05)$. Post hoc analysis revealed a statistically significant difference between time points $60 \mathrm{~min}$ and $120 \mathrm{~min}, 60 \mathrm{~min}$ and $180 \mathrm{~min}, 60$ and $240 \mathrm{~min}, 120 \mathrm{~min}$ and $180 \mathrm{~min}, 120 \mathrm{~min}$ and $300 \mathrm{~min}$, $180 \mathrm{~min}$ and $300 \mathrm{~min}, 240 \mathrm{~min}$ and $300 \mathrm{~min}$. The treatment $\mathrm{x}$ time interaction was not statistically significant.

Mean participant baseline concentration of NEFA $(\mathrm{mmol} / \mathrm{L})$ was $0.407 \pm 0.019$. A significant main effect was were found for test meal $(\mathrm{F}(3,105)=8.859 ; p<0.05)$ on serum NEFA concentration. A significant main effect was also found for time $(\mathrm{F}(4,256)=179.456 ; p<0.05)$ on NEFA serum concentration (Fig. 2b). Following the saturated fat test meal NEFA serum concentration was significantly different $(p<0.05)$ than had the participant consumed any of the other test meals. Post hoc analysis revealed a statistically significant difference between 


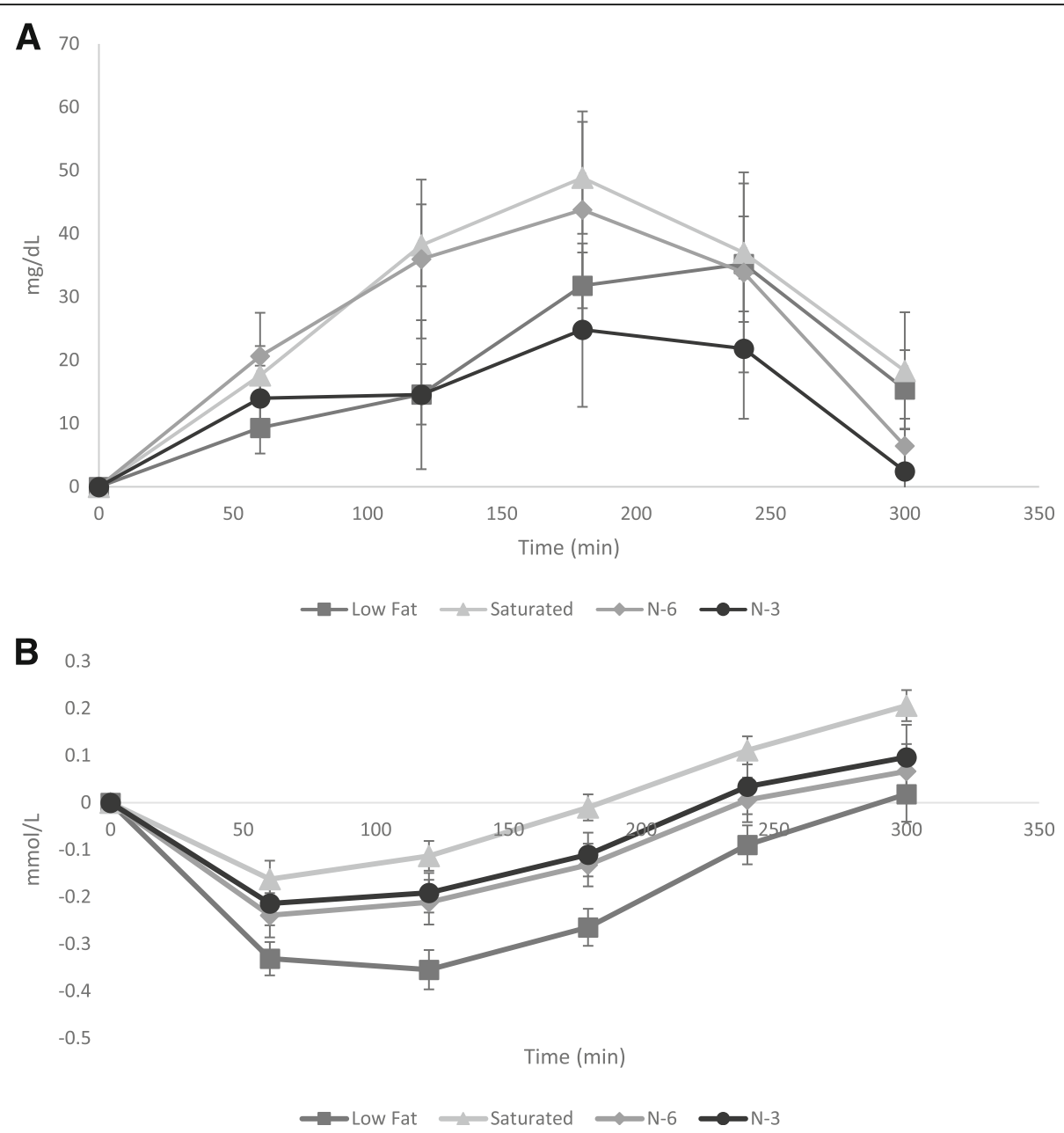

Fig. 2 Change from baseline effect of treatment meals on postprandial serum metabolite concentrations (mean \pm SEM). a Triacylglycerol (mg/dL). b Non-esterified fatty acids (mmol/L). Participant serum triacylglycerol and non-esterified fatty acids were analyzed via spectrophotometric methods. Repeated measures ANCOVA with baseline as a covariate was performed with posthoc analysis as described in Methods. Serum triacylglycerols were significantly elevated $(p<0.05)$ following the $n-6$ fatty acid rich test meal when compared to the $n-3$ fatty acid rich meal. Serum non-esterified fatty acids were significantly higher $(p<0.05)$ in the saturated fatty acid rich meal compared to the other test meals

time points $60 \mathrm{~min}$ and $180 \mathrm{~min}, 60 \mathrm{~min}$ and $240 \mathrm{~min}$, $60 \mathrm{~min}$ and $300 \mathrm{~min}, 120 \mathrm{~min}$ and $180 \mathrm{~min}, 120 \mathrm{~min}$ and $240 \mathrm{~min}, 120 \mathrm{~min}$ and $300 \mathrm{~min}, 180 \mathrm{~min}$ and $240 \mathrm{~min}, 240 \mathrm{~min}$ and $300 \mathrm{~min}$. Treatment meal $\mathrm{x}$ time point did not reach statistical significance.

\section{Discussion}

The results of this study demonstrate that the modulatory role of dietary fat intake on postprandial endogenous endotoxin concentration in healthy adult men and women is influenced by dietary fatty acid composition, but not the fat content of a meal. Although serum endotoxin was found to increase after a saturated fatty acid rich meal or decrease after an n-3 PUFA enriched meal, markers of in vivo inflammation were unaffected. Whether an elevated blood endotoxin concentration following a single high-fat meal may lead to inflammation in people is unclear as other studies have reported an association $[4,10]$ while others did not find evidence linking postprandial endotoxin with inflammation [25]. This inconsistently-described relationship may be, in part, explained because previous studies involving humans have not fully explored the role of dietary fat composition in mediating outcomes of postprandial endotoxin and inflammation. The present study therefore, to the best of our knowledge, is one of the initial studies to directly examine this relationship in humans.

A clearly observed trend was generated from the effect over time of test meal on subject postprandial serum endotoxin concentration (Table 4). The low-fat meal, which provided $20 \%$ of its energy from fat, was included in this study in order to examine whether a meal's percent energy from fat influenced postprandial endotoxin concentration. Notably, the higher-fat test meals, in which each meal provided $35 \%$ of calories from fat, 
Table 4 Effect of treatment meal on participant postprandial serum endotoxin concentration over time ${ }^{a}$

\begin{tabular}{|c|c|c|c|c|c|c|}
\hline \multirow[t]{2}{*}{ Meal } & \multicolumn{6}{|c|}{ Time postprandial (minutes) } \\
\hline & 0 & 60 & 120 & 180 & 240 & 300 \\
\hline Low Fat & $0.39 \pm 0.09$ & $0.45 \pm 0.14$ & $0.37 \pm 0.10$ & $0.28 \pm 0.03$ & $0.25 \pm 0.02$ & $0.32 \pm 0.07$ \\
\hline Saturated & $0.27 \pm 0.03$ & $0.39 \pm 0.11$ & $0.51 \pm 0.14$ & $0.49 \pm 0.17$ & $0.31 \pm 0.08$ & $0.38 \pm 0.20$ \\
\hline$N-3$ & $0.43 \pm 0.15$ & $0.29 \pm 0.07$ & $0.26 \pm 0.03$ & $0.24 \pm 0.02$ & $0.26 \pm 0.02$ & $0.26 \pm 0.02$ \\
\hline N-6 & $0.36 \pm 0.12$ & $0.59 \pm 0.20$ & $0.46 \pm 0.16$ & $0.36 \pm 0.09$ & $0.24 \pm 0.02$ & $0.31 \pm 0.09$ \\
\hline
\end{tabular}

${ }^{\text {a }}$ All values expressed as mean \pm SEM. Measured endotoxin expressed as endotoxin units $/ \mathrm{mL}$; Participant serum ( $n=20$ samples/time-point) endotoxin was determined in duplicate using the kinetic chromogenic LAL endotoxin assay. Treatment effect was analyzed following the log-transformation of measured endotoxin values using repeated measures ANCOVA with baseline as a covariate as described in Methods. The n-3 fatty acid rich test meal effected a significantly lower $(p<0.05)$ postprandial serum endotoxin than the saturated fatty acid rich test meal

were not different from the low-fat meal in their effect on postprandial serum endotoxin (data not shown). This suggests that in an isoenergetic series of meals, a higher percentage of fat does not differentially alter postprandial serum endotoxin concentration.

Among the higher-fat test meals, we found that the fatty acid composition of the meal had a significant effect on postprandial outcome serum endotoxin (Table 4). In particular, the saturated fat and n-3 fat meals elicited opposite effects on postprandial serum endotoxin. A similar relationship between saturated and n-3 fats on serum endotoxin has been previously demonstrated to occur in swine [12]. However, in mice, a diet rich in saturated fat had no significant effect on postprandial endotoxin [26]. The reasons why conflicting results would be obtained from different species is not entirely clear. The comparative similarity of study design between the swine study and the present study, which yielded similar results, included the selection of coconut oil as the saturated fat treatment, and fish oil as the n-3 fat treatment. Laugerette et al. [26] recently reported dissimilar findings when using milk-fat or palm, sunflower, and rape seed oils as dietary treatments. Specifically, saturated fat-rich palm oil resulted in the lowest blood endotoxin concentration whereas rapeseed oil, low in saturated fat, resulted in the highest blood endotoxin concentration. Another reason for conflicting results is that the measurement of serum endotoxin in swine and our present study followed ingestion of a single treatment meal, compared to mice that were fed for 8-weeks on differing dietary treatments and then endotoxemia assessed. Anatomical differences between species may also contribute to the different results obtained in each species [27, 28]. For example, mouse intestinal tract physiology is less similar to human than is that of swine [29-32].

That the n-6 meal raised postprandial endotoxin concentration but was not significantly different from other higher-fat treatments agrees with previous findings in swine where $n$-6-rich vegetable oil was not significantly different in treatment effect on serum endotoxin than n3 or saturated fat meals [12]. The postprandial trend in our data for the effect of the n-6 meal where serum endotoxin appeared higher than that of the $n-3$ treatment but lower than the saturated fat-treatment, mirrors the treatment effect trend found in swine [12].

The intestinal epithelial interface is known to play a role in immune recognition between host and non-host [33]. Toll-like receptor (TLR)-4 is one of the innate immune receptors involved in the recognition of the lipid A antigenic portion of endotoxin [34]. Lipid A often contains saturated fatty acids common in human diets [34-36]. While saturated fatty acids and n-3 PUFA have been demonstrated to reciprocally modulate human TLR-4 [34, 35], saturated non-esterified fatty acids (NEFA) in the blood of healthy Malaysian adults due to dietary fat intake did not increase inflammatory markers [36]. Likewise, in our study, n-3 and saturated fat test meals were found to effect significantly different serum NEFA but not inflammatory marker outcomes.

Test meal fat composition and postprandial changes in serum endotoxin did not associate with in vivo inflammation in any of our serum samples. While serum endotoxin concentration did uniquely change during the postprandial phase of each test meal, none of the test meals of our study caused a significant rise in endotoxin concentration when compared to baseline measurement (Table 4). One possibility for this observation was that the subjects were healthy, young, and fed only a single meal to assess postprandial endotoxin. Although a separate study reported a rise in plasma IL-6 at 120 min postprandial in healthy men after a single meal containing $33 \mathrm{~g}$ fat [37], we did not observe an associated peak of IL-6. Similar to our findings, others have reported no association between serum endotoxin and IL-6 in healthy men [5]. An intake of approximately $24 \mathrm{oz}$ of orange juice was reported to blunt the pro-inflammatory response and rise in circulating endotoxin following a high-fat meal [38]. As the present study included less than $8 \mathrm{oz}$ of orange juice as part of each test meal, it is unlikely that orange juice contributed a significant antiinflammatory effect.

The occurrence of inflammation following feeding does not appear to be dependent on changes in blood endotoxin concentrations. While in the present study we did not find a significant rise in endotoxin concentration 
following the feeding of any of the treatment meals, other studies that found postprandial increases in blood endotoxin after consumption of a single high-fat meal, likewise, did not report changes in inflammation. In male smokers, plasma CRP concentration, an acute phase protein, was not found to increase following a high-fat meal despite a significant rise in postprandial endotoxin when compared to baseline measurement [4]. Morbidly obese men that had measurable serum CRP before ingestion of a $50 \mathrm{~g}$ fat meal, but following consumption had no increase in CRP despite a significant rise in serum endotoxin [10]. The absence of an increase in inflammation, including no detectable production of CRP, in our samples may be, in part, due to the exclusion criteria in selecting for volunteers for the present study. Undetectable concentrations of TNF- $\alpha$ in human plasma have been previously reported to coincide with measurable increases in plasma endotoxin after a single high-fat meal that contained $50 \mathrm{~g}$ of butter [4]. Although endotoxin may induce in vitro IL-8 [39] and IL-10 [40] expression in human endothelial and Kupffer cells, respectively, we found no in vivo evidence of this relationship in our samples. Likewise, a separate group also reported no association between in vivo measurement of IL-8 and the feeding of a high-fat meal in humans [25]. This may suggest that human cell line production of certain pro- and anti-inflammatory cytokines after in vitro challenge by exogenous endotoxin does not adequately mimic in vivo conditions after dietary fat intake.

\section{Conclusions}

In conclusion, our results demonstrate that the composition of dietary fat, but not a meal's percent calories from fat, is significant in determining postprandial changes in blood endotoxin concentration in healthy adults in vivo. Although endotoxemia has been associated with lowgrade inflammation, we did not observe an increase or decrease in postprandial endotoxemia to modulate inflammation. As such, we could not prove a link between postprandial endotoxemia and inflammation following the consumption of a single meal unique in dietary fatty acid composition. Postprandial endotoxemia was found to be increased following consumption of a meal rich in saturated fatty acids but decreased after a meal containing n-3 polyunsaturated fatty acids. Future studies should investigate whether long-term repeated consumption of such meals would chronically influence blood endotoxin and presence of inflammation.

\section{Abbreviations}

CRP: C-reactive protein; DHA: Docosahexaenoic acid; EPA: Eicosapentaenoic acid; EU: Endotoxin unit; GC: Gas chromatograph; LAL: Limulus amebocyte lysate; NEFA: Non-esterified fatty acids; TNF-a: Tumor necrosis factor-a

\section{Funding}

This research was supported by the Agriculture and Food Research Initiative Competitive Grant No. 2014-67017-21778 from the USDA National Institute of Food and Agriculture. The USDA NIFA had no role in the design, analysis or writing of this article.

\section{Availability of data and materials}

Datasets in support of this article's conclusions are contained within this article.

\begin{abstract}
Authors' contributions
The authors' contributions were as follows: JHH, NKG, and JML contributed towards the conception and experimental design of the research. $\mathrm{JHH}$ and NKG provided all materials, laboratory reagents, and supplies. JML and JHH performed statistical analyses and interpretation of data. JML conducted the study and carried out all experiments. JML drafted the manuscript. All authors edited and approved the final manuscript.
\end{abstract}

\section{Competing interests}

The authors declare that they have no competing interests.

\section{Consent for publication}

Not applicable.

\section{Ethics approval and consent to participate}

This study was conducted according to the guidelines laid down in the Declaration of Helsinki and all procedures involving human subjects/patients were approved by the lowa State University Institutional Review Board and was registered at clinicaltrials.gov as NCT02521779. Written informed consent was obtained from all subjects/patients.

\section{Author details}

'Department of Food Science and Human Nutrition, lowa State University, Ames, IA 50011, USA. ²Department of Animal Science, lowa State University, Ames, IA 50011, USA. ${ }^{3}$ Alimentary Pharmabiotic Centre Microbiome Institute, University College Cork, Cork T12 YT20, Ireland.

Received: 12 July 2016 Accepted: 28 October 2016

Published online: 05 November 2016

\section{References}

1. Hall DM, Buettner GR, Oberley LW, Xu L, Matthes RD, Gisolfi CV. Mechanisms of circulatory and intestinal barrier dysfunction during whole body hyperthermia. Am J Physiol Heart Circ Physiol. 2001;280:H509-21.

2. Cani PD, Delzenne NM. Gut microbiota, diet, endotoxemia, and diseases. In: O'Brien PJ, Bruce WR, editors. Endogenous toxins: targets for disease treatment and prevention. Weinheim: Wiley-VCH Verlag GmbH \& Co; 2010.

3. Cani PD, Amar J, Iglesias MA, Poggi M, Knauf C, Bastelica D, Neyrinck AM, Fava F, Tuohy KM, Chabo C, et al. Metabolic endotoxemia initiates obesity and insulin resistance. Diabetes. 2007;56:1761-72.

4. Erridge C, Attina T, Spickett CM, Webb DJ. A high-fat meal induces lowgrade endotoxemia: evidence of a novel mechanism of postprandial inflammation. Am J Clin Nutr. 2007;86:1286-92.

5. Amar J, Burcelin R, Ruidavets JB, Cani PD, Fauvel J, Alessi MC, Chamontin B, Ferrieres J. Energy intake is associated with endotoxemia in apparently healthy men. Am J Clin Nutr. 2008;87:1219-23.

6. Fritsche KL. The science of fatty acids and inflammation. Adv Nutr. 2015;6: 293S-301S.

7. Vaarala O, Atkinson MA, Neu J. The "perfect storm" for type 1 diabetes: the complex interplay between intestinal microbiota, gut permeability, and mucosal immunity. Diabetes. 2008;57:2555-62.

8. Blaut M, Klaus S. Intestinal microbiota and obesity. Handb Exp Pharmacol. 2012;209:251-73.

9. Erridge C. Diet, commensals and the intestine as sources of pathogenassociated molecular patterns in atherosclerosis, type 2 diabetes and nonalcoholic fatty liver disease. Atherosclerosis. 2011;216:1-6.

10. Clemente-Postigo M, Queipo-Ortuno MI, Murri M, Boto-Ordonez M, PerezMartinez P, Andres-Lacueva C, Cardona F, Tinahones FJ. Endotoxin increase after fat overload is related to postprandial hypertriglyceridemia in morbidly obese patients. J Lipid Res. 2012;53:973-8. 
11. Moreira AP, Teixeira TF, Alves RD, Peluzio MC, Costa NM, Bressan J, Mattes R, Alfenas RC. Effect of a high-fat meal containing conventional or high-oleic peanuts on post-prandial lipopolysaccharide concentrations in overweight/ obese men. J Hum Nutr Diet. 2014;29:95-104.

12. Mani V, Hollis JH, Gabler NK. Dietary oil composition differentially modulates intestinal endotoxin transport and postprandial endotoxemia. Nutr Metab (Lond). 2013; 10:6.

13. Payette C, Blackburn P, Lamarche B, Tremblay A, Bergeron J, Lemieux I, Despres JP, Couillard C. Sex differences in postprandial plasma tumor necrosis factor-alpha, interleukin-6, and C-reactive protein concentrations. Metabolism. 2009;58:1593-601.

14. van Oostrom AJ, Sijmonsma TP, Verseyden C, Jansen EH, de Koning EJ, Rabelink TJ, Castro CM. Postprandial recruitment of neutrophils may contribute to endothelial dysfunction. J Lipid Res. 2003;44:576-83.

15. Nappo F, Esposito K, Cioffi M, Giugliano G, Molinari AM, Paolisso G, Marfella R, Giugliano D. Postprandial endothelial activation in healthy subjects and in type 2 diabetic patients: role of fat and carbohydrate meals. J Am Coll Cardiol. 2002;39:1145-50

16. Andreasen AS, Krabbe KS, Krogh-Madsen R, Taudorf S, Pedersen BK, Moller K. Human endotoxemia as a model of systemic inflammation. Curr Med Chem. 2008;15:1697-705

17. Pussinen PJ, Tuomisto K, Jousilahti P, Havulinna AS, Sundvall J, Salomaa V. Endotoxemia, immune response to periodontal pathogens, and systemic inflammation associate with incident cardiovascular disease events. Arterioscler Thromb Vasc Biol. 2007;27:1433-9.

18. Sun L, Yu Z, Ye X, Zou S, Li H, Yu D, Wu H, Chen Y, Dore J, Clement K, et al. A marker of endotoxemia is associated with obesity and related metabolic disorders in apparently healthy Chinese. Diabetes Care. 2010;33:1925-32.

19. Pussinen PJ, Havulinna AS, Lehto M, Sundvall J, Salomaa V. Endotoxemia is associated with an increased risk of incident diabetes. Diabetes Care. 2011;34:392-7

20. Schofield WN. Predicting basal metabolic rate, new standards and review of previous work. Hum Nutr Clin Nutr. 1985;39 Suppl 1:5-41.

21. Jay JM, Margitic S. Comparison of homogenizing, shaking, and blending on the recovery of microorganisms and endotoxins from fresh and frozen ground beef as assessed by plate counts and the Limulus amoebocyte lysate test. Appl Environ Microbiol. 1979;38:879-84.

22. Quantitative Analysis of Bacteria in Foods as Sanitary Indicators. United States Department of Agriculture; 2015.

23. Folch J, Lees $\mathrm{M}$, Sloane Stanley $\mathrm{GH}$. A simple method for the isolation and purification of total lipides from animal tissues. J Biol Chem. 1957;226:497-509.

24. Pogge DJ, Lonergan SM, Hansen SL. Influence of supplemental vitamin C on postmortem protein degradation and fatty acid profiles of the longissimus thoracis of steers fed varying concentrations of dietary sulfur. Meat Sci. 2014;96:956-63.

25. Fogarty $\mathrm{CL}$, Nieminen JK, Peraneva L, Lassenius MI, Ahola AJ, Taskinen MR, Jauhiainen M, Kirveskari J, Pussinen P, Horkko S, et al. High-fat meals induce systemic cytokine release without evidence of endotoxemia-mediated cytokine production from circulating monocytes or myeloid dendritic cells. Acta Diabetol. 2015;52:315-22.

26. Laugerette F, Furet JP, Debard C, Daira P, Loizon E, Geloen A, Soulage CO, Simonet C, Lefils-Lacourtablaise J, Bernoud-Hubac N, et al. Oil composition of high-fat diet affects metabolic inflammation differently in connection with endotoxin receptors in mice. Am J Physiol Endocrinol Metab. 2012;302:E374-86.

27. Nguyen TL, Vieira-Silva S, Liston A, Raes J. How informative is the mouse for human gut microbiota research? Dis Model Mech. 2015:8:1-16.

28. Miller ER, Ullrey DE. The pig as a model for human nutrition. Annu Rev Nutr. 1987;7:361-82

29. Pendyala S, Walker JM, Holt PR. A high-fat diet is associated with endotoxemia that originates from the gut. Gastroenterology. 2012;142:1100-1. e2.

30. Looft T, Allen HK, Cantarel BL, Levine UY, Bayles DO, Alt DP, Henrissat B, Stanton TB. Bacteria, phages and pigs: the effects of in-feed antibiotics on the microbiome at different gut locations. ISME J. 2014;8:1566-76.

31. Lamendella R, Domingo JW, Ghosh S, Martinson J, Oerther DB. Comparative fecal metagenomics unveils unique functional capacity of the swine gut. BMC Microbiol. 2011;11:103.

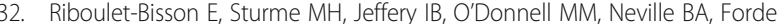
BM, Claesson MJ, Harris H, Gardiner GE, Casey PG, et al. Effect of Lactobacillus salivarius bacteriocin Abp118 on the mouse and pig intestinal microbiota. PLoS One. 2012;7:e31113.
33. Abreu MT, Fukata M, Arditi M. TLR signaling in the gut in health and disease. J Immunol. 2005:174:4453-60.

34. Huang S, Rutkowsky JM, Snodgrass RG, Ono-Moore KD, Schneider DA, Newman JW, Adams SH, Hwang DH. Saturated fatty acids activate TLRmediated proinflammatory signaling pathways. J Lipid Res. 2012;53:2002-13.

35. Munford RS, Hall CL. Detoxification of bacterial lipopolysaccharides (endotoxins) by a human neutrophil enzyme. Science. 1986;234:203-5.

36. Voon PT, Ng TK, Lee VK, Nesaretnam K. Diets high in palmitic acid (16:0), lauric and myristic acids (12:0 + 14:0), or oleic acid (18:1) do not alter postprandial or fasting plasma homocysteine and inflammatory markers in healthy Malaysian adults. Am J Clin Nutr. 2011;94:1451-7.

37. Laugerette F, Vors C, Geloen A, Chauvin MA, Soulage C, Lambert-Porcheron $\mathrm{S}$, Peretti N, Alligier M, Burcelin R, Laville $\mathrm{M}$, et al. Emulsified lipids increase endotoxemia: possible role in early postprandial low-grade inflammation. J Nutr Biochem. 2011:22:53-9.

38. Ghanim H, Sia CL, Upadhyay M, Korzeniewski K, Viswanathan P, Abuaysheh S, Mohanty P, Dandona P. Orange juice neutralizes the proinflammatory effect of a high-fat, high-carbohydrate meal and prevents endotoxin increase and Toll-like receptor expression. Am J Clin Nutr. 2010;91:940-9.

39. Hippenstiel S, Soeth S, Kellas B, Fuhrmann O, Seybold J, Krull M, EichelStreiber C, Goebeler M, Ludwig S, Suttorp N. Rho proteins and the p38MAPK pathway are important mediators for LPS-induced interleukin-8 expression in human endothelial cells. Blood. 2000;95:3044-51.

40. Knolle P, Schlaak J, Uhrig A, Kempf P, Buschenfelde KH M z, Gerken G Human Kupffer cells secrete IL-10 in response to lipopolysaccharide (LPS) challenge. J Hepatol. 1995:22:226-9.

\section{Submit your next manuscript to BioMed Central and we will help you at every step:}

- We accept pre-submission inquiries

- Our selector tool helps you to find the most relevant journal

- We provide round the clock customer support

- Convenient online submission

- Thorough peer review

- Inclusion in PubMed and all major indexing services

- Maximum visibility for your research

Submit your manuscript at www.biomedcentral.com/submit
) Biomed Central 